\title{
Anthocyanin Intramolecular Interactions. A New Mathematical Approach To Account for the Remarkable Colorant Properties of the Pigments Extracted from Matthiola incana
}

\author{
Paulo Figueiredo ${ }^{\dagger}$ Mourad Elhabiri, $^{\dagger}$ Norio Saito, ${ }^{\ddagger}$ and Raymond Brouillard ${ }^{*}, \dagger$ \\ Contribution from the Laboratoire de Chimie des Polyphénols, associe au CNRS, \\ Universite Louis Pasteur, Institut de Chimie, 1, rue Blaise Pascal, 67008 Strasbourg, France, \\ and the Chemical Laboratory, Meiji-Gakuin University, Totsuka-ku, Yokohama, Japan
}

Received October 19, $1995^{\otimes}$

\begin{abstract}
In the last few years, a series of investigations has brought to light a mechanism of stabilization of the colorant properties of certain anthocyanins. Intramolecular interactions take place between the chromophore moiety of the anthocyanin and one of its aromatic acid residues, which folds over the chromophore and thus confers protection against hydration and subsequent formation of colorless forms. In our continuing study of the physicochemical properties exhibited by acylated natural anthocyanins, we report here on a series of five structurally related pigments extracted from the violet flowers of Matthiola incana. These pigments all bear the same chromophore moiety, i.e., the cyanidin aglycon, but differ in the degree of glycosylation and acylation. Acidity constants for the deprotonation and hydration equilibria of the flavylium cation, together with rate constants for the hydration step alone were determined from UV-visible absorption measurements. The data support the existence of intramolecular, noncovalent interactions that strongly stabilize the colored forms of the pigments. However, none of the four more heavily substituted anthocyanins follows the above-mentioned mechanism that was previously successfully applied to the study of acylated anthocyanins. Consequently, a new mechanism with a different mathematical treatment is here developed to account for the different behavior exhibited by these distinctive pigments.
\end{abstract}

\section{Introduction}

Anthocyanins, glycosylated polyhydroxy derivatives of 2 phenylbenzopyrylium (flavylium) salts, are the pigments responsible for most of the wide variety of colors displayed by flowers and fruits, where they are naturally produced. 1,2 However, when extracted from plant material, the most common anthocyanins (3-monoglucosides and 3,5-dighucosides) are almost colorless in mildly acidic equilibrated aqueous solution at room temperature, conditions similar to the ones observed in plant cells. This color loss is due to an hydration reaction (Scheme 1) of the colored flavylium cation, which produces the colorless forms hemiacetal and chalcones. ${ }^{3-5}$

In order to explain the remarkable color stability of anthocyanins in nature, several studies were performed in model solutions containing the pigments and some natural colorless molecules, currently known as copigments. ${ }^{1,6-10}$ The results

\footnotetext{
$\dagger$ Université Louis Pasteur.

¥ Meiji-Gakuin University.

${ }^{\otimes}$ Abstract published in Advance ACS Abstracts, May 1, 1996.

(1) Brouillard, R.; Dangles, O. In The Flavonoids, Advances in Research Since 1986; Harborne, J. B., Ed.; Chapman and Hall: London, 1993; pp 565-588.

(2) Goto, T.; Kondo, T. Angew. Chem., Int. Ed. Engl. 1991, 30, 17-33.

(3) Brouillard, R.; Dubois, J. E. J. Am. Chem. Soc. 1977, 99, 13591364 .

(4) Brouillard, R.; Delaporte, B. J. Am. Chem. Soc. 1977, 99, 84618468 .

(5) Brouillard, R.; Delaporte, B.; Dubois, J. E. J. Am. Chem. Soc. 1978, 100, 6202-6205.

(6) Brouillard, R.; Mazza, G.; Saad, Z.; Albrecht-Gary, A. M.; Cheminat, A. J. Am. Chem. Soc. 1989, 111, 2604-2610.

(7) Brouillard, R.; Wigand, M. C.; Dangles, O.; Cheminat, A. J. Chem. Soc., Perkin Trans. 2 1991, 1235-1241.

(8) Mistry, T. V.; Cai, Y.; Lilley, T. H.; Haslam, E. J. Chem. Soc., Perkin Trans. 2 1991, 1287-1296.

(9) Dangles, O.; Brouillard, R. Can. J. Chem. 1992, 70, 2174-2189.

(10) Wigand, M. C.; Dangles, O.; Brouillard, R. Phytochemistry 1992,

$31,4317-4324$.
}

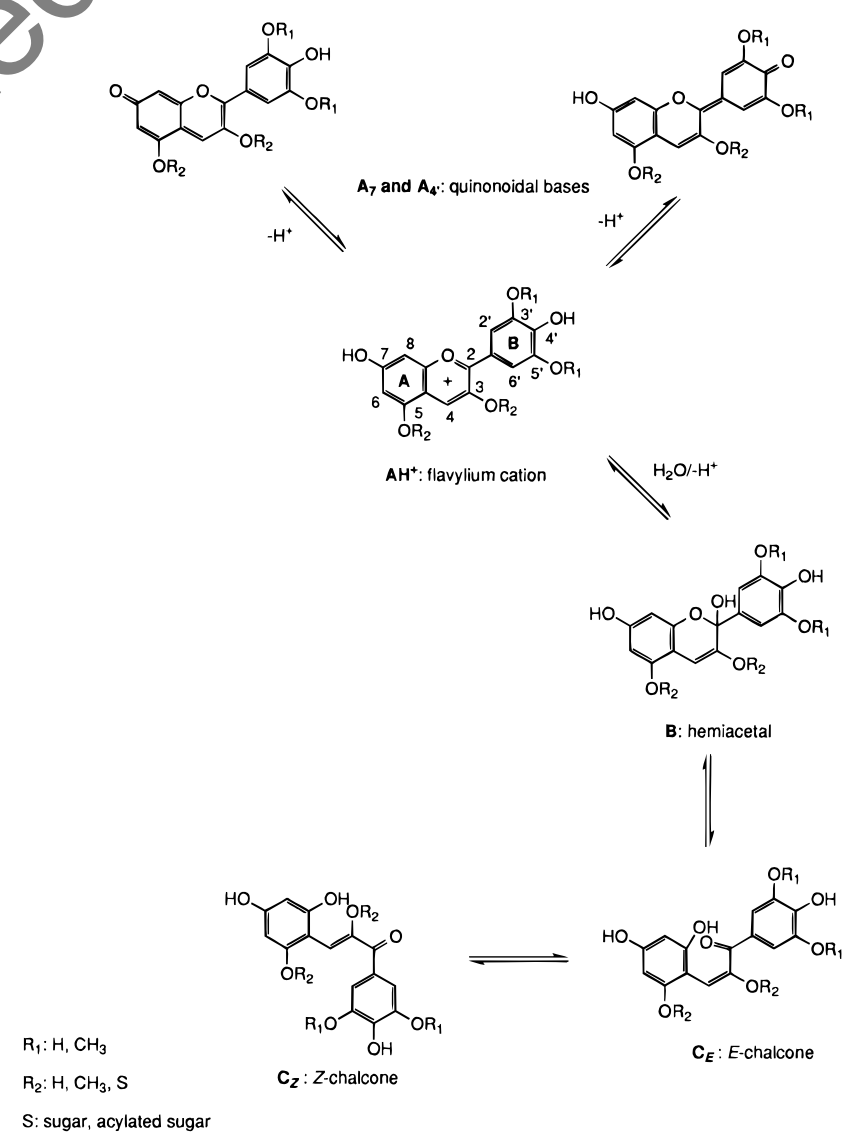

obtained, using UV-visible and ${ }^{1} \mathrm{H}$ NMR spectrometries, evidenced the existence of an intermolecular noncovalent interaction (copigmentation) between the anthocyanin and 


\section{Chart 1}
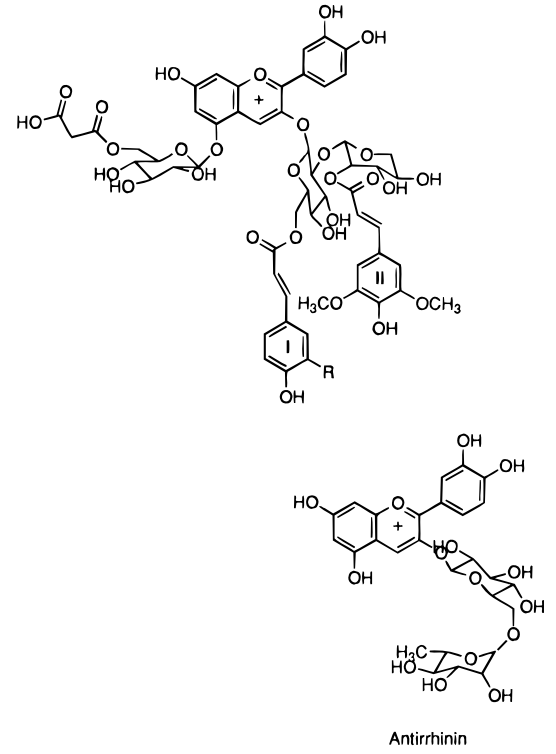

copigment molecules. Such hydrophobic complexation efficiently protects the chromophore against the nucleophilic water attack, thus displacing the equilibria of Scheme 1 toward the formation of more flavylium molecules.

Since the last decade, with the improvement of extraction and purification techniques, far more complex anthocyanin structures, which gave stable colored solutions at mildly acidic $\mathrm{pH}$ values, were discovered and characterized.1,11-15 Most of these pigments possess cinnamic and/or malonic acid residues esterified to the sugars. The flexible saccharide chains act as linkers allowing the folding of the acyl aromatic rings over the planar pyrylium ring, as evidenced by the existence of NOEs in ${ }^{1} \mathrm{H}$ NMR between the aglycon protons and those of the acids. ${ }^{16,17}$ The formation of such intramolecular copigmentation complexes thus protects the chromophore against fydration in an even more efficient way than that conferred by intermolecular copigmentation. ${ }^{14}$

The following equations account for the transformations undergone by anthocyanin molecules in mildly acidic aqueous solutions:

$$
\begin{gathered}
\mathrm{AH}^{+} \stackrel{K_{\mathrm{a}}}{\rightleftharpoons} \mathrm{A}+\mathrm{H}^{+} \\
\mathrm{AH}^{+}+\mathrm{H}_{2} \mathrm{O} \stackrel{K_{\mathrm{h}}}{\rightleftharpoons}\left(\mathrm{B}+\mathrm{C}_{E}\right)+\mathrm{H}^{+}
\end{gathered}
$$

Since the ring opening of B to form the $E$-chalcone occurs in a very fast step, ${ }^{18,19}$ we write the equilibrium as a whole for the sake of clarity; $C_{Z}$, which is usually formed in very small amounts ${ }^{20}$ is neglected. All the acylated molecules studied until

(11) Harborne, J. B.; Grayer, R. J. In The Flavonoids, Advances in Research Since 1980; Harborne, J. B., Ed.; Chapman and Hall: London, 1988; pp 1-20.

(12) Strack, D.; Wray, V. In The Flavonoids, Advances in Research Since 1986; Harborne, J. B., Ed.; Chapman and Hall: London, 1993; pp 1-22. 124.

(13) Dangles, O.; Saito, N.; Brouillard, R. Phytochemistry 1993, 34, 119-

(14) Dangles, O.; Saito, N.; Brouillard, R. J. Am. Chem. Soc. 1993, 115, $3125-3132$.

(15) Figueiredo, P.; Elhabiri, M.; Toki, K.; Saito, N.; Dangles, O.; Brouillard, R. Phytochemistry 1996, 41, 301-308.

(16) Goto, T.; Tamura, H.; Kawai, T.; Hoshino, T.; Harada, N.; Kondo, T. Ann. N. Y. Acad. Sci. 1986, 471, 155-173.

(17) Yoshida, K.; Kondo, T.; Goto, T. Tetrahedron 1992, 48, 43134326.

(18) McClelland, R. A.; Devine, D. B.; Sorensen, P. E. J. Am. Chem. Soc. 1985, 107, 5459-5463.

(19) Brouillard, R.; Lang, J. Can. J. Chem. 1990, 68, 755-761.
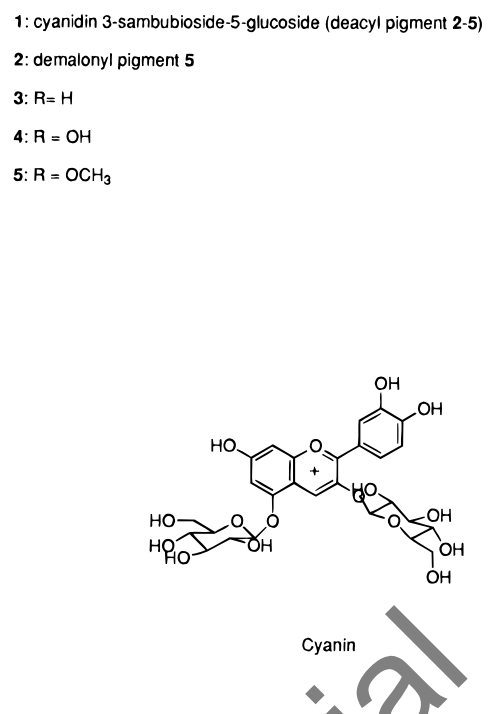

now present a decrease in the value of $K_{\mathrm{h}},{ }^{13-15}$ and only minimal changes in the deprotonation constant $K_{\mathrm{a}}$, which signifies that the interaction between the two moieties of the pigment, while in the flavylium cation form, proceeds through hydrophobic stacking and not through hydrogen bonding, since the existence of free OHgroups in the aglycon is a requisite for formation of the quinonoidal bases, A (Scheme 1).

The present work reports on the first known group of acylated anthocyanins that represents a deviation to this, until now, general behavior. The five pigments, which constitute a structurally homogeneous series based on the cyanidin $\left(3,5,7,3^{\prime}, 4^{\prime}\right.$ pentahydroxyflavylium) aglycon, were extracted from the violet flowers of Matthiola incana. ${ }^{21}$ Their structures (Chart 1), fully elucidated by ${ }^{1} \mathrm{H}$ NMR techniques and FAB-MS, are 3-O-(2$O$ - $\beta$-D-xylopyranosyl- $\beta$-D-glucopyranosyl)-5- $O-\beta$-D-glucopyranosyl cyanidin (1), 3-O-(6-O-(trans-ferulyl)-2-O-(2-O-(transsinapyl)- $\beta$-D-xylopyranosyl)- $\beta$-D-glucopyranosyl)-5- $O-\beta$-Dglucopyranosyl cyanidin (2), 3-O-(6-O-(trans- $p$-coumaryl)-2$O$-(2-O-(trans-sinapyl)- $\beta$-D-xylopyranosyl)- $\beta$-D-glucopyranosyl)5- $O$-(6- $O$-(malonyl)- $\beta$-D-glucopyranosyl cyanidin (3), 3- $O$-(6$O$-(trans-caffeyl)-2- $O$-(2- $O$-(trans-sinapyl)- $\beta$-D-xylopyranosyl)$\beta$-D-glucopyranosyl)-5- $O$-(6- $O$-(malonyl)- $\beta$-D-glucopyranosyl cyanidin (4), and 3-O-(6-O-(trans-ferulyl)-2-O-(2-O-(transsinapyl)- $\beta$-D-xylopyranosyl)- $\beta$-D-glucopyranosyl)-5- $O$-(6- $O$ (malonyl)- $\beta$-D-glucopyranosyl cyanidin (5). The thermodynamic and kinetic data gathered are compared to the ones obtained for cyanidin 3,5-diglucoside (cyanin), one of the most common anthocyanins that can be considered a simpler structural analogue, and reveal not only a marked increase in the value of $K_{\mathrm{a}}$ for the more complex pigments but also an otherwise unknown effect of acidity-dependent interaction, which prompted us to discuss the results obtained in the light of a new mechanistic and mathematical approach.

\section{Experimental Section}

Materials. Pigments 1-5 were isolated from the violet flowers of Matthiola incana according to a published procedure. ${ }^{21}$ Their purity, always superior to $98 \%$, was checked by ${ }^{1} \mathrm{H}$ NMR spectroscopy. Cyanidin 3,5-diglucoside, henceforth referred to as cyanin, was a kind gift of Prof. Sam Asen and was used without further purification, and

(20) Santos, H.; Turner, D. L.; Lima, J. C.; Figueiredo, P.; Pina, F. S.; Maçanita, A. L. Phytochemistry 1993, 33, 1227-1232.

(21) Saito, N.; Tatsuzawa, F.; Nishiyama, A.; Yokoi, M.; Shigihara, A.; Honda, T. Phytochemistry 1995, 38, 1027-1032. 
Table 1. Maximum Visible Wavelength and Molar Absorption Coefficient for the Flavylium Cation Form of the Seven Anthocyanins ${ }^{a}$

\begin{tabular}{lcccrrrr}
\hline & \multicolumn{9}{c}{ pigment } \\
\cline { 2 - 7 } & cyanin & antirrhinin & $\mathbf{1}$ & $\mathbf{2}$ & $\mathbf{3}$ & $\mathbf{4}$ \\
\hline$\lambda_{\max } / \mathrm{nm}$ & 508 & 510 & 522 & 528 & 536 & 538 & 538 \\
$\epsilon_{\mathrm{AH}}+\mathrm{mol}^{-1} \mathrm{dm}^{3} \mathrm{~cm}^{-1}$ & $35000^{24}$ & 7000 & 3600 & 15100 & 19000 & 21200 & 20100 \\
\hline
\end{tabular}

${ }^{a} \mathrm{pH}=0.9$.

cyanidin 3-rutinoside (antirrhinin) was synthesized following an elsewhere described method. ${ }^{22}$ All other reagents used were of analytical grade.

Absorption Spectra. Spectra were recorded with a Hewlett-Packard diode-array spectrometer fitted with a quartz cell $(d=1 \mathrm{~cm})$ equipped with a stirring magnet. A constant temperature of $25( \pm 0.1){ }^{\circ} \mathrm{C}$ was obtained by use of a Lauda water-thermostated bath. Temperature was measured with a Comark thermocouple.

Thermodynamic Measurements. Mother solutions of $\mathrm{ca} .5 \times 10^{-4}$ $\mathrm{M}$ of all the anthocyanins were prepared in $0.1 \mathrm{M} \mathrm{HCl}$ and left to equilibrate in the dark for about $2 \mathrm{~h}$. Then, for each pigment 10 solutions were prepared by 1:10 dilutions of the mother solutions with different volumes of a $\mathrm{NaOH} 0.1 \mathrm{M}$ solution and $\mathrm{H}_{2} \mathrm{O}$ so that the final $\mathrm{pH}$ covered a range of 1.0-4.0. After equilibration in the dark, the UV-visible spectra of these solutions were recorded. The values of the hydration equilibrium constants $\left(K_{\mathrm{h}}\right)$ are gained from measuring the relative hyperchromic shift at the visible absorption maxima as a function of $\mathrm{pH}$.

Kinetic Measurements. One milliliter of each equilibrated aqueous solution of anthocyanin, at different $\mathrm{pH}$ values $(1.0-2.5)$, is magnetically stirred in the spectrophotometer cell. The concentrations of the pigments are $6.4 \times 10^{-5} \mathrm{M}$ for $1,1.7 \times 10^{-5} \mathrm{M}$ for $2,1.8 \times 10^{-5} \mathrm{M}$ for $3,4.05 \times 10^{-5} \mathrm{M}$ for $4,4.9 \times 10^{-5} \mathrm{M}$ for $\mathbf{5}, 5.0 \times 10^{-5} \mathrm{M}$ for cyanin, and $6.3 \times 10^{-5} \mathrm{M}$ for antirrhinin. To these solutions $1 \mathrm{~mL}$ of phosphate buffer solutions, ranging in $\mathrm{pH}$ from 4.3 to 7.4 , was quickly added, and the visible absorbance at $520 \mathrm{~nm}$ (near the visible absorption maxima for all the studied anthocyanins) is immediately recorded every second over $120 \mathrm{~s}$, to guarantee that the hydration equilibrium is attained. The final $\mathrm{pH}$ was then measured and ranged from 2.3 to 4.4 . The exponential decay of the absorbance essentially reflects the relaxation of the $\mathrm{pH}$-dependent equilibrium depicted in eq 2 according to an apparent first-order kinetics. The spectrophotometer software automatically computes the first-order apparent rate constant of the hydration reaction $(k)$. The theoretical treatment that ensues for the obtention of the equilibrium rate constants is given in full detail in ref 14.

Molecular Orbitals Calculations. Molecular mechanics, using the $\mathrm{MM}+$ force field, ${ }^{23}$ both in vacuo and in a simulated water solution contained within a periodic box, were performed on an Escom Pentium 100 PC using the HyperChem program (Version 4, Hypercube, Inc., Ontario, Canada).

\section{Results}

Thermodynamic Data. The visible absorption band characteristic of these pigments presents for these series of anthocyanins ( $\mathbf{1}-\mathbf{5}$ plus cyanin and antirrhinin), which share the same chromophore (cyanidin) but differ in the pattern of glycosylation and acylation, a bathochromic shift (Table 1) when going from the simpler (cyanin) to the structurally more complicated (5). This shift is a property evidenced by the majority of the complexes formed by the most common anthocyanins. ${ }^{1}$ Such red shift is generally accompanied by a small decrease in the molar absorption coefficient $(\epsilon)$ which indicates that the complexed forms, either resulting from inter- or intramolecular associations, exhibit a slightly less intense coloration than their corresponding free flavylium cations. However, this small decrease in absorption intensity at very acidic $\mathrm{pH}$ values is largely compensated by the gain of color obtained in mildly acidic solutions. Nevertheless, in the present series of pigments

(22) Elhabiri, M.; Figueiredo, P.; Fougerousse, A.; Brouillard, R. Tetrahedron Lett. 1995, 36, 4611-4614.

(23) Allinger, N. L. J. Am. Chem. Soc. 1977, 99, 8127-8134.

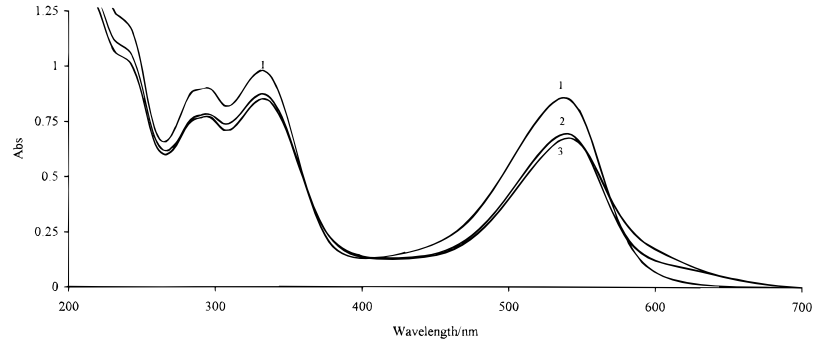

Figure 1. Electronic absorption spectra of $4\left(4.05 \times 10^{-5} \mathrm{M}, T=25\right.$ ${ }^{\circ} \mathrm{C}$ ) in aqueous solution. $1, \mathrm{pH} 0.8 ; 2, \mathrm{pH} 1.35 ; 3, \mathrm{pH} 2.4$.

here reported, there is one (pigment 1) where the hypochromic effect is far more stronger, exhibiting an $\epsilon c a$. ten times smaller than that published for cyanin 4 (Table 1). Such a large drop in the value of the absorption coefficient seems to be a general characteristic of the molecules possessing a disaccharide as a substituent group in position 3 of the chromophore, since a similar pattern was already noticed in two other anthocyanins presenting an analogous substitution pattern (delphinidin 3-gentiobioside and antirrhinin). ${ }^{15,22}$ Although no other values for molecules with a structure similar to $\mathbf{1}$ are of our knowledge, this effect seems to be more intense when there is also a glycosyl residue in position 5, since when comparing 1 with antirrhinin, which shares the same chromophore, the first shows an $\epsilon$ value of roughly $50 \%{ }^{25}$ that of the latter (Table 1 ).

When applied to anthocyanins in mildly acidic aqueous solutions, a plot of $D_{0} /\left(D_{0}-D\right)$ vs $\left[\mathrm{H}^{+}\right]$, where $D$ is the maximum of the visible absorbance at a given $\mathrm{pH}$ and $D_{0}$ is the absorbance at $\mathrm{pH}<1$, gives a straight line that, through an already established procedure, ${ }^{13-15}$ enables the obtention of a global constant $\left(K^{\prime}=K_{\mathrm{h}}+K_{\mathrm{a}}\right)$ which allows the determination of the equilibrium fractional amount of $\mathrm{AH}^{+}$at a given $\mathrm{pH}$ value. However, when this method is applied to the present set of pigments a deviation from linearity is registered for molecules 2-5, while it gives good correlations when $\mathbf{1}$, antirrhinin, and cyanin are concerned. This particular behavior is accompanied by the observation of a sharp drop in intensity of the visible absorption band of pigments $\mathbf{2}-\mathbf{5}$ when the $\mathrm{pH}$ is increased from a value around 0.7 , where the flavylium cation is the sole absorbing species, to a value of $c a$. 1.5, remaining then almost unchanged until attainment of a $\mathrm{pH}$ superior to $\sim 2$ as shown in Figure 1 for pigment 4.

For solutions with a less acidic $\mathrm{pH}(\sim 2.1-3.5)$ it is clearly noticed the appearance of a shoulder, on the right hand side of the visible band, which increases with the $\mathrm{pH}$ and is accompanied by a gradual diminution of the flavylium cation absorption (Figure 2a). This new band is characteristic of the quinonoidal base form of the anthocyanins. Moreover, if the flavylium contribution is subtracted from the whole spectra, according to a procedure detailed elsewhere, ${ }^{26}$ the remaining spectra show distinctively the formation of the quinonoidal base at very low $\mathrm{pH}$ values (Figure $2 \mathrm{~b}$ ), which deeply contrasts with

(24) Brouillard, R.; El Hage Chahine, J. M. J. Am. Chem. Soc. 1980, $102,5375-5378$.

(25) Due to the low amount of the available sample, it was only possible to estimate an approximate value of $\epsilon_{\lambda_{\max }} \approx 3600$ for $\mathbf{1}$.

(26) Figueiredo, P.; Pina, F.; Vilas-Boas, L.; Maçanita, A. L. J. Photochem. Photobiol., A: Chemistry 1990, 52, 411-424. 

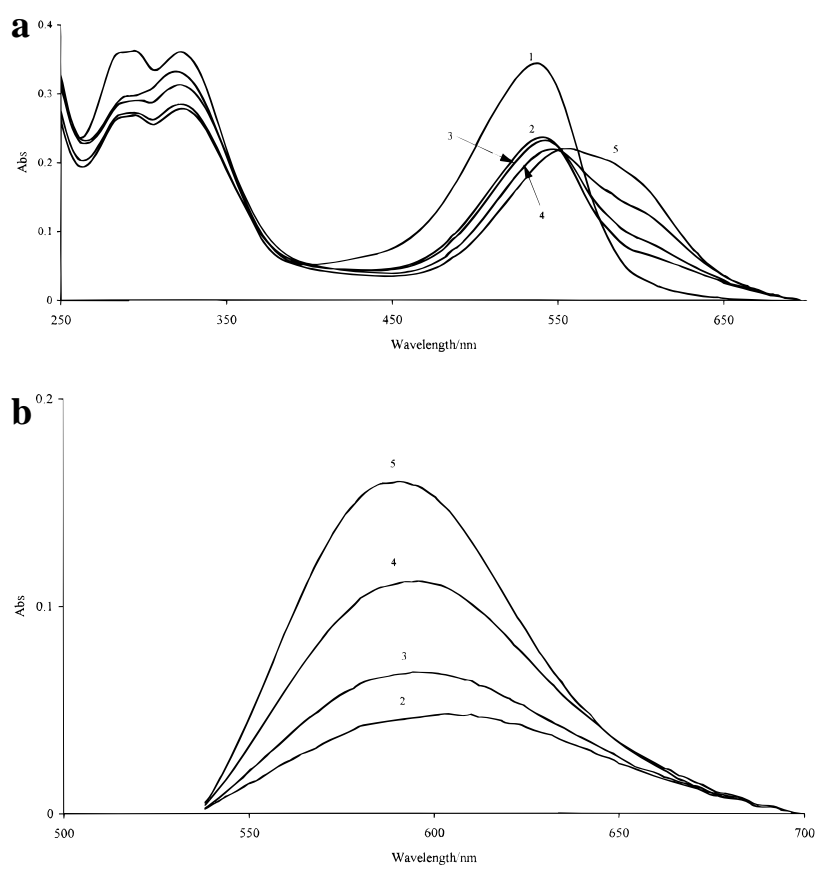

Figure 2. Electronic absorption spectra of $3\left(1.8 \times 10^{-5} \mathrm{M}, T=25\right.$ ${ }^{\circ} \mathrm{C}$ ) in aqueous solution, before (a) and after (b) the subtraction of the flavylium cation absorption. $1, \mathrm{pH} 0.8 ; 2, \mathrm{pH} 1.6 ; 3, \mathrm{pH} 2.0 ; 4, \mathrm{pH}$ 2.8; 5, pH 3.5.

the, until now, generally observed formation of this form at a $\mathrm{pH}$ closer to neutrality. ${ }^{2}$

The observation of these distinctive characteristics for anthocyanins $\mathbf{2}-\mathbf{5}$ together with the unapplicability of the model postulated in ref 14 led us to bring forth the following hypothesis of mechanism to account for the behavior of the four pigments, as a function of $\mathrm{pH}$, in acidic aqueous solutions

$$
\mathrm{CP}+\mathrm{H}_{2} \mathrm{O} \stackrel{K_{\mathrm{h}}}{\rightleftharpoons} \mathrm{B}+\mathrm{H}^{+}
$$

with $K_{1}=[\mathrm{CP}] /\left[\mathrm{AH}^{+}\right], K_{\mathrm{h}}^{\mathrm{CP}}=[\mathrm{B}]\left[\mathrm{H}^{+}\right] /[\mathrm{CP}]$, and $K_{\mathrm{a}}^{\mathrm{CP}}=$ $[\mathrm{A}]\left[\mathrm{H}^{+}\right] /[\mathrm{CP}]$. In eq 4 the fast equilibrating $\mathrm{B}$ and $\mathrm{C}_{E}$ forms are simply represented by $\mathrm{B}$ for the sake of clarity. Equation 3 accounts for the assumed equilibrium between two conformations of the flavylium cation, one with an acyl residue folded over the chromophore in the form of an intramolecular complex (CP), with a smaller $\epsilon$ value than that of the other conformation $\left(\mathrm{AH}^{+}\right)$which is not copigmented. $\mathrm{AH}^{+}$has its domain of existence only in very acidic media $(\mathrm{pH}<1)$, while $\mathrm{CP}$ dominates in the $\mathrm{pH}$ region 1.0-2.0. This would explain the sudden drop of absorbance verified when going from very acidic to slightly less acidic solutions. It will be the intramolecular copigmentation complex thus formed that undergoes the usual reactions - eqs 4 and 5- of hydration and deprotonation depicted in Scheme 1.

Equations 6-8 represent the overall concentration of pigment $\left(C_{\mathrm{T}}\right)$, the visible absorption of an anthocyanin solution for a given $\mathrm{pH}(D)$, and at $\mathrm{pH}<1\left(D_{0}\right)$, where only $\mathrm{AH}^{+}$absorbs

$$
\begin{gathered}
C_{\mathrm{T}}=\left[\mathrm{AH}^{+}\right]+[\mathrm{CP}]+[\mathrm{A}]+[\mathrm{B}] \\
D=\epsilon_{\mathrm{AH}}{ }^{+}\left[\mathrm{AH}^{+}\right]+\epsilon_{\mathrm{CP}}[\mathrm{CP}]+\epsilon_{\mathrm{A}}[\mathrm{A}]
\end{gathered}
$$

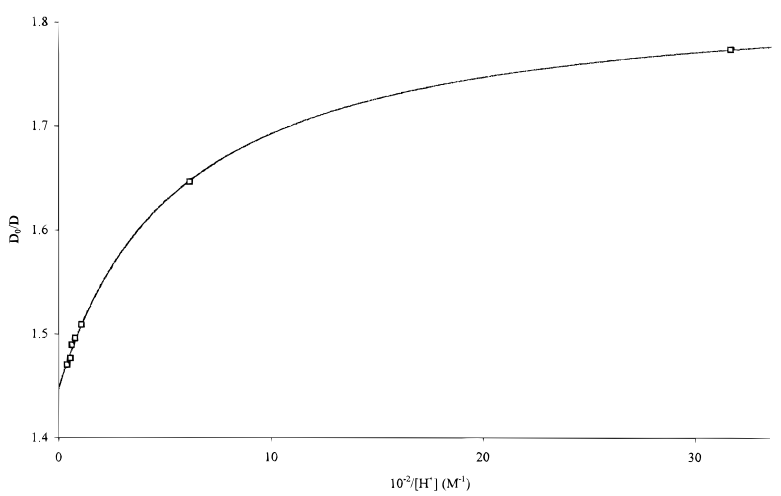

Figure 3. Plot of $D_{0} / D$ as a function of $1 /\left[\mathrm{H}^{+}\right]$for pigment $\mathbf{5}$, according to eq 10 .

\begin{tabular}{|c|c|c|c|}
\hline & \multicolumn{3}{|c|}{ pigment } \\
\hline & 2 & 4 & 5 \\
\hline$K_{1}$ & $b$ & 8.77 & 8.20 \\
\hline $\mathrm{p} K^{\prime}$ & 1.98 & 1.91 & 1.94 \\
\hline$R$ & 0.998 & 0.998 & 0.999 \\
\hline
\end{tabular}

Table 2. Thermodynamic Parameters Obtained from Eq 10 for Pigments $\mathbf{2}-\mathbf{5}^{a}$

${ }^{a} T=25{ }^{\circ} \mathrm{C} .{ }^{b}$ Pigment 2 gives a $K_{1}=1.15$; see text for discussion.

$$
D_{0}=\epsilon_{\mathrm{AH}}+{ }^{+} \mathrm{C}_{\mathrm{T}}=\epsilon_{\mathrm{AH}}{ }^{+}\left(\left[\mathrm{AH}^{+}\right]+[\mathrm{CP}]+[\mathrm{A}]+[\mathrm{B}]\right)
$$

we can rearrange eq 7 as

$$
\mathrm{D}=\epsilon_{\mathrm{AH}}{ }^{+}\left(\left[\mathrm{AH}^{+}\right]+\epsilon_{\mathrm{CP}} / \epsilon_{\mathrm{AH}}{ }^{+}[\mathrm{CP}]+r_{\mathrm{A}}[\mathrm{A}]\right)
$$

where $r_{\mathrm{A}}$ stands for the ratio $\epsilon_{\mathrm{A}} / \epsilon_{\mathrm{AH}}{ }^{+}$. A combination of eqs 8 and 9, together with the expressions above defined for the equilibrium constants $K_{1}, K_{\mathrm{h}}^{\mathrm{CP}}$, and $K_{\mathrm{a}}^{\mathrm{CP}}$, gives eq 10 .

$$
\frac{D_{0}}{D}=\frac{\frac{1}{K_{1}}+1+\frac{1}{\left[\mathrm{H}^{+}\right]}\left(K_{\mathrm{h}}^{\mathrm{CP}}+K_{\mathrm{a}}^{\mathrm{CP}}\right)}{\frac{1}{K_{1}}+\frac{\epsilon_{\mathrm{CP}}}{\epsilon_{\mathrm{AH}^{+}}}+\frac{1}{\left[\mathrm{H}^{+}\right]} r_{\mathrm{A}} K_{\mathrm{a}}^{\mathrm{CP}}}
$$

A plot of $D_{0} / D$ vs $1 /\left[\mathrm{H}^{+}\right]$, for pigments $\mathbf{2}-\mathbf{5}$, produces a fitting of the experimental data (Figure 3 ), with very good correlations $(R)$, from where the values of $K_{1}$ and $K^{\prime}=K_{\mathrm{h}}^{\mathrm{CP}}+K_{\mathrm{a}}^{\mathrm{CP}}$ could be obtained (Table 2).

Kinetic Data. The $\mathrm{pH}$ jumps conducted at constant temperature for all the pigments studied produce, without exception, an exponential decay of the visible absorbance, caused by the $\mathrm{pH}$-dependent hydration reaction. However, the ensemble of kinetic data gathered, like the thermodynamic ones, should be analyzed according to two different models. Thus, cyanin, antirrhinin, and $\mathbf{1}$ follow the treatment, presented elsewhere, ${ }^{14}$ which uses eq 11 to fit the data gained from the spectrophotometric analysis.

$$
\frac{\left(K_{\mathrm{a}}+K_{\mathrm{h}}+\left[\mathrm{H}^{+}\right]\right)}{k}=\frac{1}{k_{2}}+\frac{1 K_{\mathrm{a}}}{\left[\mathrm{H}^{+} k_{2}\right.}
$$

In eq $11, k_{2}$ represents the dehydration rate constant as defined by the ratio $K_{\mathrm{h}}=k_{1} / k_{2}$, where $k_{1}$ defines the rate constant for the direct process (hydration). By plotting $\left(K_{\mathrm{a}}+K_{\mathrm{h}}+\left[\mathrm{H}^{+}\right]\right) / k$ vs $1 /\left[\mathrm{H}^{+}\right]$one can obtain directly $k_{2}$ and $K_{\mathrm{a}}$ and, together with the values obtained from the plot of $D_{0} /\left(D_{0}-D\right) v s\left[\mathrm{H}^{+}\right]$, above mentioned, also the values for $K_{\mathrm{h}}$ and $k_{1}$.

For the remaining pigments $(\mathbf{2}-\mathbf{5})$ it is necessary to take into account the reaction scheme proposed in eqs $3-5$, which leads 
Table 3. Thermodynamic and Kinetic Values Obtained for the Cyanidin Based Anthocyanins ${ }^{a}$

\begin{tabular}{|c|c|c|c|c|c|c|c|}
\hline & \multicolumn{7}{|c|}{ pigment } \\
\hline & antirrhinin $^{b}$ & cyanin $^{b}$ & $\mathbf{1}^{b}$ & 2 & 3 & 4 & 5 \\
\hline $\mathrm{p} K_{\mathrm{h}}^{\mathrm{CP}}$ & $2.93( \pm 0.02)$ & $2.07( \pm 0.02)$ & $1.29( \pm 0.02)$ & $2.04( \pm 0.01)$ & $1.78( \pm 0.01)$ & $2.84( \pm 0.01)$ & $2.75( \pm 0.02)$ \\
\hline $\mathrm{p} K_{3}^{\mathrm{CP}}$ & $3.58( \pm 0.03)$ & $4.03( \pm 0.02)$ & $4.57( \pm 0.06)$ & $2.88( \pm 0.01)$ & $2.26( \pm 0.02)$ & $1.96( \pm 0.01)$ & $2.01( \pm 0.02)$ \\
\hline$k_{1}^{\mathrm{CP}} \times 10^{2} / \mathrm{min}^{-1}$ & $1.01( \pm 0.01)$ & $2.92( \pm 0.03)$ & $4.93( \pm 0.06)$ & $7.85( \pm 0.03)$ & $38.52( \pm 0.27)$ & $4.26( \pm 0.02)$ & $3.49( \pm 0.03)$ \\
\hline$k_{2}^{\mathrm{CP}} \times 10^{4} / \mathrm{M}^{-1} \mathrm{~min}^{-1}$ & $8.68( \pm 0.07)$ & $3.45( \pm 0.03)$ & $0.95( \pm 0.01)$ & $8.55( \pm 0.03)$ & $21.41( \pm 0.15)$ & $29.65( \pm 0.15)$ & $19.42( \pm 0.16)$ \\
\hline
\end{tabular}

${ }^{a} T=25^{\circ} \mathrm{C} .{ }^{b}$ The superscript $\mathrm{CP}$ does not apply in those cases.

to the following treatment for the experimental data obtained through the spectrophotometric measurements.

Equation 12 describes the relaxation process of the hydration equilibrium after a $\mathrm{pH}-\mathrm{jump}$

$$
\frac{\mathrm{d}[\mathrm{B}]}{\mathrm{dt}}=k_{1}^{\mathrm{CP}}[\mathrm{CP}]-k_{2}^{\mathrm{CP}}[\mathrm{B}]\left[\mathrm{H}^{+}\right]
$$

with $K_{\mathrm{h}}^{\mathrm{CP}}=k_{1}^{\mathrm{CP}} / k_{2}^{\mathrm{CP}}$. If the principle of mass conservation is expressed as

$$
\Delta\left[\mathrm{AH}^{+}\right]+\Delta[\mathrm{CP}]+\Delta[\mathrm{A}]+\Delta[\mathrm{B}]=0
$$

one can combine eqs 12 and 13 to obtain the apparent firstorder rate constant $k^{\mathrm{CP}}$ as defined by $\mathrm{d} \Delta[\mathrm{B}] / \mathrm{d} t=-k^{\mathrm{CP}} \Delta[\mathrm{B}]$. It comes in the form

$$
k^{\mathrm{CP}}=k_{2}^{\mathrm{CP}}\left[\mathrm{H}^{+}\right]\left\{\frac{K_{\mathrm{a}}^{\mathrm{CP}}+K_{\mathrm{h}}^{\mathrm{CP}}+\left[\mathrm{H}^{+}\right]\left(1+\frac{1}{K_{1}}\right)}{K_{\mathrm{a}}^{\mathrm{CP}}+\left[\mathrm{H}^{+}\right]\left(1+\frac{1}{K_{1}}\right)}\right\}
$$

Equation 14 can be written in the following way

$$
\frac{K_{\mathrm{a}}^{\mathrm{CP}}+K_{\mathrm{h}}^{\mathrm{CP}}+\left[\mathrm{H}^{+}\right]\left(1+1 / K_{1}\right)}{k^{\mathrm{CP}}}=\frac{1+1 / K_{1}}{k_{2}^{\mathrm{CP}}}+\frac{K_{\mathrm{a}}^{\mathrm{CP}}}{k_{2}^{\mathrm{CP}}} \frac{1}{\left[\mathrm{H}^{+}\right]}
$$

Thus, a plot of $\left\{K_{\mathrm{a}}^{\mathrm{CP}}+K_{\mathrm{h}}^{\mathrm{CP}}+\left[\mathrm{H}^{+}\right]\left(1+1 / K_{\mathrm{l}}\right)\right\} / k^{\mathrm{CP}}$ as a function of $1 /\left[\mathrm{H}^{+}\right]$yields a straight line with an intercept of $(1$ $\left.+1 / K_{1}\right) / k_{2}^{\mathrm{CP}}$, from where the value of $k_{2}^{\mathrm{CP}}$ can be readily obtained if one takes the value for $K_{1}$ obtained from eq 10 , and a slope equal to $K_{\mathrm{a}}^{\mathrm{CP}} / k_{2}^{\mathrm{CP}}$, which leads immediately to the values for $K_{\mathrm{a}}^{\mathrm{CP}}, K_{\mathrm{h}}^{\mathrm{CP}}$, and $k_{1}^{\mathrm{CP}}$. The values obtained for the thermodynamic and kinetic constants of all the pigments studied are presented in Table 3 .

\section{Discussion}

Water, in its liquid state, is generally considered as a structured network of hydrogen-bonded molecules ${ }^{27-29}$ responsible for the specificity of most biological processes. It is also known that even minor physical or chemical changes can disrupt this particular three-dimensional organization and thus inactivate these processes. ${ }^{28}$ Intermolecular copigmentation, a phenomenon driven by hydrophobic interactions, is likewise dependent on solvent arrangement, being more strong at temperatures near $0{ }^{\circ} \mathrm{C}$ than at room temperature, since at the former water is a quasi-crystalline medium which shows favor to the interaction between anthocyanin and copigment. ${ }^{6,7}$ Given this reasoning, it is possible to think of the " $\mathrm{pH}$ dependent" intramolecular copigmentation of the flavylium cation form of anthocyanins $\mathbf{2} \mathbf{- 5}$, as associated to a change in the particular framework of liquid water caused by the increase in acidity which will give rise to a less organized solvent structure, at very acidic $\mathrm{pH}$

(27) Rice, S. A. In Topics in Current Chemistry; Vol. 60, Structure of Liquids; Springer-Verlag: Berlin, 1975; pp 109-200.

(28) Franks, F. Water; The Royal Society of Chemistry: London, 1984.

(29) Scheiner, S. Annu. Rev. Phys. Chem. 1994, 45, 23-56.

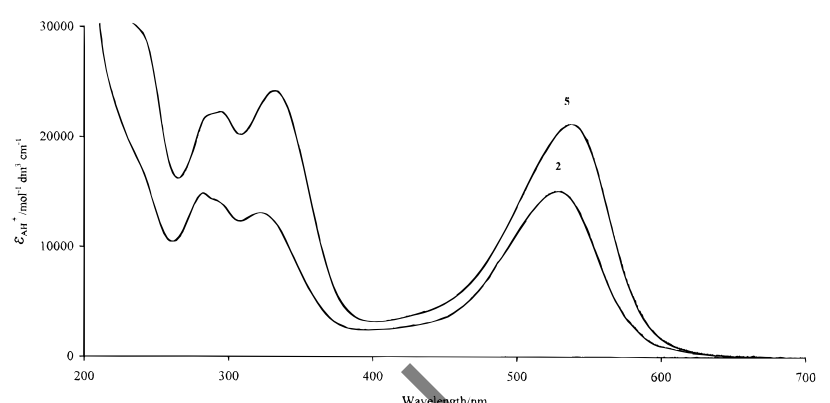

Figure 4. Electronic absorption spectra of the flavylium forms of 2 and 5 in aqueous solution. pH $0.9, T=25^{\circ} \mathrm{C}$.

values, thus hindering the folding of the acyl residue over the chromophore.

From the analysis of the data presented in Table 2, it is evident a common value of $K_{1} \sim 8.0-9.0$ for pigments 3,4 , and 5 seems to justify the meehanism conjectured above, eqs 3-5. Pigment 2 has a $K_{1}$ of 1.15 and a spectrophotometric behavior intermediate between what is typically reported for other anthocyanins and the spectral characteristics of compounds 3-5. Nevertheless, the theoretical interpretation of the absorption gain $v s \mathrm{pH}$, for this molecule, is better achieved through the application of eq $10(R=0.9986)$ than by the use of the formalism reported in refs $13-15(R=0.9920)$. This predicts an important role for malonyl residues on the formation of intramolecular complexes by anthocyanins, since this is the sole difference between pigments $\mathbf{2}$ and $\mathbf{5}$ (3 and $\mathbf{4}$ are also structurally closer to 5). The influence of the malonyl group is already manifest when comparing the spectra of the flavylium cations of $\mathbf{2}$ and 5 (Figure 4), notably the band at ca. $320 \mathrm{~nm}$, characteristic of the acylated anthocyanins, which is less intense than the one at $280 \mathrm{~nm}$ for 2, while the inverse happens with 3, 4, and 5. Such increase in band intensity could be used as an empirical tool for the characterization of simultaneously acylated and malonylated anthocyanins.

The data reported in Table 3 allows the following assumptions: (i) The well-known increase in $\mathrm{p} K_{\mathrm{h}}$ when going from 3,5-diglucosylated molecules to 3-glucosylated ones, ${ }^{15,30}$ can also be extended to antirrhinin (relatively to cyanin), which possesses a particular type of disaccharide (a rutinose) bound to position 3. (ii) $\mathrm{A}$ very low $\mathrm{p} K_{\mathrm{h}}$ value for 1 , which can now be considered as a distinguishing feature of some types of 3-disaccharides, which possess the ability of preferential stabilization of the hemiacetal form by formation of intramolecular hydrogen bonds between the hemiacetalic $\mathrm{OH}$ and one of the free hydroxyls of the terminal sugar. ${ }^{15}$ Molecular mechanics calculations, performed in a simulated aqueous solution, with several possible structural conformations, yielded for the conformation with the lower enthalpy value, a distance of $3.18 \AA$ between the above two hydroxyl groups, which is generally considered as being capable of accommodating an hydrogen bond. ${ }^{27-29}$ Similar calculations, performed with antirrhinin, showed no such behavior, this being attributed to

(30) Dangles, O.; Elhajji, H. Helv. Chim. Acta 1994, 77, 1595-1610. 
the presence of a terminal $\mathrm{CH}_{3}$ group, instead of an hydroxyl, in the sugar position favorable for the formation of an $\mathrm{H}$ bond. (iii) The $\mathrm{p} K_{\mathrm{h}}^{\mathrm{CP}}$ values increase in the order $\mathbf{3}, \mathbf{2}, \mathbf{5}$, and 4 . Although $k_{1}^{\mathrm{CP}}$ (hydration step) values are all larger (even considerably larger in the case of pigment 3 ) than the one found for cyanin ( $k_{1}$ in that case), this is somehow compensated by the also larger values calculated for $k_{2}^{\mathrm{CP}}$. This behavior can be interpreted through the analysis of the data collected from molecular modelization of the four pigments, and the comparison of the structures with the minimum relative enthalpies obtained for each compound. These results evidence the existence, for all those four anthocyanins, of a "sandwich" structure with the two aromatic acyl residues positioned on each side of the chromophore, thus protecting it from hydration, the difference in protection being given by the relative position of the acid ring I relative to the B-ring of the aglycon, the closer it is the lesser the efficiency of the nucleophilic attack. ${ }^{31}$ This closeness also increases in the order $\mathbf{3}, \mathbf{2}, \mathbf{5}$, and $\mathbf{4}$. This increase in vicinity of the two aromatic rings is accompanied, and presumably caused, by an increasing proximity between the final carbonyl group of the malonyl residue and the 7-OH of the aglycon. (iv) Since the hydroxyl groups in positions $4^{\prime}$ and 7 are the ones that participate in the deprotonation equilibria to form the quinonoidal bases, ${ }^{32,33}$ the relative proximity of the malonyl to the 7-OH, with the possibility of $\mathrm{H}$ bond formation, should increase the charge density in C-7 and thus facilitate the deprotonation, ${ }^{34}$ with the concomitant decrease in $\mathrm{p} K_{\mathrm{a}}$ (Table 3). This assumption is further stressed by the inspection of the values computed for the above mentioned interatomic distances, which are respectively $3.43 \AA$ for pigment $\mathbf{4}, 3.60 \AA$ for $\mathbf{5}$, and

(31) Molecular mechanics calculations, performed in our laboratory, for the intermolecular interactions between several simple (albeit with a noncoplanar B ring as is the case with the present set) anthocyanins and common copigments such as chlorogenic acid and caffeine, have demonstrated a preferential interaction between the $\mathrm{B}$ ring of the pigment and the aromatic residue(s) of the copigment.

(32) Kurtin, W. E.; Song, P.-S. Tetrahedron 1968, 24, 2255-2267.

(33) Costantino, L.; Rastelli, G.; Rossi, M. C.; Albasini, A. J Chem. Soc., Perkin Trans. 2 1995, 227-234.

(34) The molecular modelization, in AM1 parametrization, ${ }^{35}$ of a simple polyhydroxylated anthocyanidin ( $3^{\prime}, 4^{\prime}, 3,7$-tetrahydroxyflavylium) forming an hydrogen bond, through its $7-\mathrm{OH}$, with a malonate, produces a relative increase on the charge density of C-7 from 0.167 to 0.195 , while the other free hydroxyl groups of the cation, notably the $4^{\prime}-\mathrm{OH}$, remain almost unchanged.

(35) Dewar, M. J. S.; Zoebisch, E. G.; Healy, E. F.; Stewart, J. J. P. J. Am. Chem. Soc. 1985, 107, 3902-3909.
4.72 for $\mathbf{3}$, following the increase in $\mathrm{p} K_{\mathrm{a}}$. Since molecule $\mathbf{2}$ does not possess a malonyl residue, its $\mathrm{p} K_{\mathrm{a}}$ is higher than the ones calculated for the above three pigments, although lower than the ones obtained for cyanin or $\mathbf{1}$. This peculiar interaction reveals an important role for malonyl residues in natural colorants, since this lowering of the $\mathrm{p} K_{\mathrm{a}}$, together with the protection against color loss by hydration, allows the existence of colored forms (flavylium cation or quinonoidal base) through a very large range of acidic $\mathrm{pH}$ values. The cornerstone of the mechanism of color stabilization and variation in the case of this series of pigments rests on the formation of the quinonoidal bases at low $\mathrm{pH}$ values. This is true for instance in the case of compound 3 which has a $\mathrm{p} K_{\mathrm{h}}^{\mathrm{CP}}$ value lower than the one found for cyanin. However, the loss of color stability, related to the lowering of the $\mathrm{p} K_{\mathrm{h}}^{\mathrm{CP}}$ value is, in that case, largely compensated by the decrease in the $\mathrm{p} K_{\mathrm{a}}^{\mathrm{CP}}$ value when going from cyanin to pigment 3 . Finally, it should be noted also the small differences between $\mathrm{p} K_{\mathrm{a}}^{\mathrm{CP}}$ and $\mathrm{p} K_{\mathrm{h}}^{\mathrm{CP}}$ for pigments $\mathbf{2 - 5}$. This is an important characteristic feature of color stabilization and variation within the flowers of the Matthiola incana species.

\section{Conclusions}

The formation of intramolecular complexes, which prevent the loss of color through hydration reactions, by natural anthocyanins possessing at least one aromatic acyl residue linked through sugar spacers at the aglycon moiety is here evidenced, especially for compounds $\mathbf{4}$ and $\mathbf{5}$, which not only evidence the already known effect of increase in $\mathrm{p} K_{\mathrm{h}}$ but, furthermore constitute, from our knowledge, the two sole natural anthocyanins that present a value for their $\mathrm{p} K_{\mathrm{a}}$ lower than that of the $\mathrm{p} K_{\mathrm{h}}$. Moreover, a role for the simple, nonaromatic, malonyl residue, related to this property, is also disclosed for the first time in the present work. A new mathematical treatment of a new equilibrium mechanism, complementary to the one already employed for the characterization of similar pigments, ${ }^{13-15}$ is also presented to account for the particular properties of the set of molecules here discussed.

Acknowledgment. The authors wish to express their gratitude to Prof. Sam Asen for the kind gift of a sample of cyanin. Paulo Figueiredo wishes also to thank the European Union for a post-doc grant ERBCHBICT941610.

JA9535064 